\title{
LA ARISTOCRACIA GALORROMANA ANTE LAS MIGRACIONES BÁRBARAS DEL SIGLO V: LA “INVENCIÓN” DEL BURGUNDIO
}

\author{
Gallo-Roman aristocrats and fifth century Barbarian migrations: the "invention" of the \\ Burgundians
}

\author{
Jesús HERNÁNDEZ LOBATO \\ Universidad de Salamanca \\ parvuslupus@hotmail.com
}

Fecha de recepción: 19-01-2010

Fecha de aceptación: 29-01-2010

\begin{abstract}
RESUMEN: La presente comunicación se propone elucidar el papel de la poesía tardoantigua en la construcción social del "otro" bárbaro, esencial en la crisis identitaria del bajo Imperio Romano. Nos centraremos para ello en el cáustico carmen 12 de Sidonio Apolinar (430/431-489 d. C.), más comúnmente conocido como la "sátira de los Burgundios". Esta pieza compuesta en torno al año 461 denuncia en clave de humor la extrema precariedad que atravesaba la maltratada capital lionesa ante la presencia masiva en sus calles y plazas de refugiados burgundios, que habían pasado de la noche a la mañana a enseñorearse de la colapsada ciudad galorromana, imponiendo a cada paso sus "incívicos" usos y costumbres. El poema -de una amarga comicidad - nos revela la frustración de un aristócrata nostálgico, que -ansioso por preservar el legado cultural del mundo romano- debe afrontar los cambios que necesariamente comporta la presencia de ese gran "otro" en el horizonte del Imperio y confesar, en último término, la inviabilidad de su proyecto, la imposibilidad de la poesía. Partiendo del evidente sesgo ideológico de este prisma literario, intentaremos reconstruir la historia del colectivo humano de los burgundios, uno de los más pujantes y creativos del panorama protogermánico.
\end{abstract}

Palabras Clave: burgundios, Antigüedad tardía, civilización galorromana, migraciones bárbaras, Sidonio Apolinar, construcción identitaria, poesía, siglo V

ABSTRACT: This paper aims to elucidate the role of late Antique poetry in the social 
construction of the Barbarian "other", a crucial point in the identity crisis of the late Roman Empire. To this end, I focus on Sidonius Apollinaris' (430/431-489 AD) caustic carmen 12, better known as "The Satire of Burgundians" (written around 461 AD). This poem -full of a bitter humour- shows the frustration of a nostalgic aristocrat, who -although eager to preserve the rich cultural legacy of the Roman world- must face the changes necessarily brought up by the appearance of this new "other" on the Western horizon. Ultimately, the poet is even compelled to confess the unfeasibility of his project, the impossibility of poetry. Taking the obvious ideological bias of this literary perspective as a starting point, I try to reconstruct the internal history of Burgundians, one of the most enterprising and creative human groups on the Proto-Germanic scene.

Keywords: Burgundians, Late Antiquity, Gallo-Roman civilization, Barbarian migrations, Sidonius Apollinaris, Identity construction, Poetry, 5th century

Los burgundios son un pueblo germano cuya capital importancia en el devenir cultural europeo contrasta con una visible escasez documental y con una lamentable ausencia de restos materiales de envergadura. De ahí que el estudio de su cultura se convierta en un estimulante reto para antropólogos e historiadores. Su ingreso en la historia de Occidente, esto es, su primera aparición en los textos escritos, no se produce hasta que entran en contacto con la potente maquinaria del Imperio Romano, el gran posesor de la palabra escrita (otro de sus muchos procedimientos de dominio y homologación cultural). Se trata del momento en el que los pueblos germanos comenzaban a constituir el punto de mira predominante para la construcción de la identidad tambaleante de Roma, como antes lo habían sido los griegos y los orientales. El Imperio, en medio de una de su mayores crisis políticas, sujeto a profundos cambios religiosos (implantación progresiva del cristianismo, ruptura del foedus con las deidades paganas) y sociales (asentamiento masivo de pueblos germanos dentro de su limes, ruralización, mestizaje cultural), debe reconstruir su identidad a través de su contraste con el "otro", el "bárbaro", el dorso de la moneda. Contamos, para dar cuenta de este proceso identitario basado en la "alteridad", con el precioso testimonio del poeta galorromano Sidonio Apolinar (430/431-489 d. C.), que vio con sus propios ojos cómo su ciudad natal, Lyon (Lugdunum), se llenaba de unos ubicuos pobladores burgundios, que importaban su lengua, su cultura y sus costumbres. El carmen 12 de Sidonio tiene mucho que decirnos sobre el modo efectivo en que la cultura de los burgundios se veía desde fuera, qué tópicos sociales mediaban en su percepción y cómo éstos contribuían a forjar -desde la alteridad y la diferencia- la identidad nacional de un Imperio tocado de muerte. Pero, ¿quiénes eran en realidad esos burgundios a los que satiriza el poema? ¿Cuál había sido su recorrido por la historia antes de topar con la pluma de Sidonio?

Los burgundios eran un pueblo germánico oriental originario de la 
isla de Bornholm (al sur de Suecia). Descendieron tempranamente de las orillas del Báltico (siglo I d. C.) a las riveras del Oder y el Vístula (en la actual Polonia), donde se asentaron a mediados del siglo III de nuestra era. Allí de acuerdo con el testimonio del historiador romano del siglo VI Jordanes en su De origine actibusque Getarum $(16,97)$ - fueron batidos por Fastida, rey de los getas, que prácticamente los llevó a la aniquilación. Menguados en número y fuerzas, emigraron hasta el valle del Rhin durante el movimiento generalizado de pueblos germanos del siglo IV, conocido con el nombre alemán de Völkerwanderung. Allí se asentaron en torno a la ciudad de Worms (Borbetomagus), destacada en el Cantar de los Nibelungos (Nibelungenlied) como capital del reino burgundio. Parece ser que en este contexto estaba ya bien avanzado el proceso de evangelización de los pueblos germánicos emigrados, que abrazaron la herejía arriana, futura fuente de disputa con el catolicismo del Imperio de Occidente. Pero sin lugar a dudas la fuerza de la religiosidad antigua debío de hacerse notar aún en buena parte de la sociedad burgundia, que vivía una situación de transición cultural perfectamente reflejada en el célebre Nibelungenlied, corpus de leyendas germanas parcialmente cristianizadas (situación intermedia de aculturación religiosa).

La vida de los asentamientos burgundios en la Renania, considerados foederati colindantes con el limes Romanus (marcado por la ribera del Rhin), se desarrollaba en un difícil tira y afloja con el gobierno imperial. La influencia de los foederati bárbaros en la política de Roma se hacía más visible y decisoria a medida que el núcleo gubernamental del Imperio iba perdiendo su poder fáctico y su efectividad administrativa. Así, en el año 411, el rey burgundio Gondahar, aliado con Goar, rey de los Alanos, consiguió situar en el trono de Roma al galo Jovino, un emperador títere afín a sus propósitos. Gracias al control efectivo que Gondahar ejercía a través de dicho monarca, el asentamiento burgundio en la ribera occidental del Rhin, entre los ríos Lauter y Nahe (territorio romano), se oficializó, dando pie a incursiones cada vez más audaces contra la provincia de la Galia superior y Bélgica; la base del poder burgundio en aquella época era la ciudad renana de Worms (Borbetomagus), de fundación romanocéltica. Cuando la presión sobre esta zona del Imperio se hizo insostenible, el general galo Aecio contrató los servicios de mercenarios húnicos, que saquearon el territorio renano de los burgundios y destruyeron su capital, Worms, en 437. Incontables burgundios perecieron en la batalla, entre ellos su propio rey Gondahar. Este desastre para el pueblo burgundio dio pie a la transmisión de diversas leyendas y relatos sobre la caída de Worms, cristalizados algunos siglos después en El cantar de los Nibelungos (cfr. infra): en él, el rey Gunther de Burgundia, cuya corte reside en Worms, resulta ser el trasunto literario del propio Gondahar. El relato concluye con la venganza de Crimilda, viuda del héroe Sigfrido (asesinado por la misma codicia de oro que llevó en la realidad al rey Gondahar a devastar las riquezas de la Galia): ésta, desposada ahora con el rey Etzel de los hunos 
(claro trasunto de Atila), se sirve del poder de su marido para acabar con los burgundios y recuperar el tesoro de Sigfrido; el rey burgundio muere y su corte es destruida.

Los refugiados burgundios supervivientes de la catástrofe, bajo el mando del nuevo rey Gunderico y con el beneplácito de Roma, emigran hacia el sur y se asientan en las inmediaciones de la ciudad de Lyon (Lugdunum), importante centro cultural del Imperio tardoantiguo. Cuando los hunos comenzaron a hacerse demasiado peligrosos para la estabilidad del Imperio y asolaban a su paso amplias regiones de la propia Penínula Itálica, el general galo Aecio, causante último de la destrucción de Worms, no dudó en conciliar a sus antiguos enemigos (los burgundios) y a los visigodos, asentados en la Galia, en una confederación bélica que frenase el avance de Atila hacia sus territorios. El éxito de esta alianza, que logró lo que ninguna otra del Imperio había conseguido, fue completo: Atila fue ampliamente derrotado en 451 en la batalla de los Campos Cataláunicos (Chalons), y se vio forzado a emprender la retirada ${ }^{1}$. Las alianzas de los burgundios con el poder de Roma no siempre fueron tan firmes, y existía en general el tópico étnico de que los germanos no eran gente de fiar que respetase la fides (la palabra dada), algo que Roma había achacado sistemáticamente a todos sus enemigos exteriores (celtas, orientales, númidas...): era un elemento de contraste con el "otro" que el Imperio empleó siempre para construir su propia identidad. El propio Sidonio Apolinar, uno de cuyos poemas analizaremos en este trabajo, se sirvió de ese tópico en su panegírico al emperador Avito, que había combatido con Aecio contra los hunos 2 .

Pese a esa desconfianza mutua entre romanos y burgundios sus causas volvieron a unirse con relativa frecuencia. Así, cuando parte de la aristocracia gala se confabuló contra el nuevo emperador de Occidente, Mayoriano, desfavorable a sus intereses políticos (había derrocado del trono imperial a Avito, suegro de Sidonio Apolinar y héroe nacional en la Galia por su intervención contra los hunos), los cabecillas del movimiento no dudaron en aliarse con los burgundios para conseguir sus propósitos comunes. El monarca sofocó esta conjura (conocida como Coniuratio Marcelliniana) cargando contra la ciudad de Lyon, que, como sede de la disensión opositora, había admitido a numerosos burgundios en su seno. Los burgundios fueron expulsados y la ciudad devastada (458); poco a poco, gracias a la labor mediadora del diplomático Pedro, se fue readmitiendo a los burgundios en las proximidades de la castigada ciudad. A la muerte de Mayoriano, todos fueron readmitidos de golpe, creándose un fuerte choque cultural en la ciudad de Lyon, del que el poeta y aristócrata Sidonio Apolinar nos ha dejado testimonio escrito. Se trata del poema que analizaremos brevemente en la segunda parte de nuestro trabajo, que refleja con mucho sentido del humor las dificultades de esa mezcla de culturas característica del Bajo Imperio y los pro- 
cedimientos identitarios que surgen en este tipo de contactos interétnicos. El punto de vista, por supuesto, es el del propio Sidonio, defensor acérrimo de los valores de la Romanidad y contario a la pérdida de los refinamientos culturales del Imperio.

Los pactos de los distintos pueblos bárbaros entre sí no fueron mucho más firmes. Los cabecillas burgundios Chilperico y Gundioco acompañaron al rey visigodo Teodorico cuando éste se lanzó a la conquista de Hispania en 455 (año en que los vándalos saquearon Roma ante la indiferencia de los burgundios). Pocas décadas después los visigodos se convirtieron en enemigos comunes de burgundios y francos, ahora emparentados por matrimonio (la hija de Chilperico, Clotilda, con el rey franco Clovis). Lyon acabó por ser la capital del nuevo reino burgundio en torno al 461. El reino no tendría, sin embargo, una gran continuidad temporal: tan sólo ocho reyes de la casa de Gondahar accedieron al trono burgundio hasta el momento de su total erradicación, precisamente a manos de los francos, sus antiguos aliados, en 534. Desde ese momento el reino de Burgundia queda subsumido entre los reinos merovingios, en una fusión política y étnica que acabó totalmente con su conciencia de pueblo autónomo.

Por lo demás, las descripciones de Amiano nos presentan a los burgundios como un pueblo más civilizado que sus compañeros germanos ${ }^{3}$. Pero es muy posible que esa descripción esté filtrada por intereses políticos y prejuicios personales, como bien ha señalado SANTOS, 1990:110. El testimonio crítico de Sidonio, con el que contribuiremos en este trabajo a la elucidación de la "invención" tardoantigua del burgundio, nos revelará -desde una perspectiva que Unamuno describiría como intrahistórica- la realidad de la convivencia entre romanos y burgundios, y la profunda "alteridad" de los unos a ojos de los otros. Es obvio que un autor como Amiano, que hablaba de los burgundios desde la distancia y la conveniencia política, podía permitirse una mayor idealización de sus informaciones. En cambio, el contacto directo y autobiográfico de Sidonio nos brinda una imagen más descarnada y cotidiana, extremadamente valiosa para un estudio de este tipo. Por todo ello, su cáustico carmen 12, más conocido como "Sátira de los Burgundios", constituye un perfecto testimonio intrahistórico sobre la construcción romana del "otro" burgundio. Veámoslo.

\section{AD CATVLLINVM}

Quid me, etsi ualeam, parare carmen

Fescenninicolae iubes Diones

inter crinigeras situm cateruas

et Germanica uerba sustinentem, 
laudantem tetrico subinde uultu

quod Burgundio cantat esculentus,

infundens acido comam butyro?

$V$ is dicam tibi quid poema frangat?

Ex hoc barbaricis abacta plectris

10 spernit senipedem stilum Thalia,

ex quo septipedes widet patronos.

Felices oculos tuos et aures

Felicemque libet nocare nasum,

cui non allia sordidumque cepe

15 ructant mane nouo decem apparatus,

quem non ut uetulum patris parentem

nutricisque virum die nec orto

tot tantique petunt simul Gigantes,

quot uix Alcinoi culina ferret.

20 Sed iam Musa tacet tenetque habenas

paucis hendecasyllabis iocata,

ne quisquam satiram uel hos nocaret.

Antes de proceder a nuestra tarea, resultará imprescindible referir con brevedad el contexto socio-político en que se inserta el poema, al ser éste un elemento esencial para la recta intelección de su contenido y de la motivación pragmática de su escritura; la pieza persigue, de hecho, denunciar con humor una situación tremendamente conflictiva y delicada, ante la cual ya sólo cabe o bien el distanciamiento irónico o la risa desencantada. ¿Cuál era, pues, esa compleja situación de crisis?

Ya hemos señalado cómo la pujante aristocracia galorromana y muy en particular nuestro poeta se habían sentido íntimamente ligados al proyecto imperial de su compatriota (y suegro, en el caso de Sidonio) Avito, en quien habían depositado todas sus esperanzas y aspiraciones. Avito -conviene recordarlo- había ascendido al trono tras el éxito de la coalición de burgundios, visigodos y romanos contra las hordas de Atila, liderada pr Aecio, en la que desempeñó un papel fundamental. De ahí que galos y burgundios sintieran como una ofensa personal su violenta deposición, a tan sólo un año de su 
toma de poder, a manos de una coalición liderada por el comes domesticorum Mayoriano y el astuto Ricimer, quienes, unidos a la celosa aristocracia itálica y con el callado beneplácito del emperador de Oriente, quisieron arrebatarles a los senadores galorromanos su recién adquirida influencia dentro la esfera del poder y su creciente capacidad de decisión sobre los asuntos del Imperio. Así pues, la batalla de Plasencia (Plaisance) -17 de octubre de 456- no sólo supondría la derrota definitiva del propio Avito (relegado desde entonces a un intrascendente obispado), sino también el truncamiento del poder efectivo de la aristocracia gala en Occidente y la retirada completa del ámbito de la vida pública de nuestro Sidonio, parte destacada del bando de los vencidos, vinculado como estaba por parentesco y cargo cívico al emperador derrocado. Mayoriano, que accedió a las fasces imperiales tras unos largos meses de tenso vacío de poder ${ }^{4}$, habría de perdonarle la vida (cfr. carm. $4^{5}$ ), en parte por congraciarse mediante este gesto con la humillada aristocracia galorromana (personificada en uno de sus más eximios y populares representantes), en parte para poder disponer en el futuro de los servicios literarios de nuestro poeta con evidentes fines propagandísticos, para los que ya había demostrado estar sobradamente dotado. No es de extrañar que gran parte de la contestaria elite de Auvernia y Narbona se resistiera con encono a aceptar al nuevo monarca (investido como tal en diciembre de ese difícil 456) y tramara una conjura, con el apoyo inestimable de burgundios (concentrados por aquel entonces en torno a la ciudad de Lyon con el consentimiento de sus habitantes) y visigodos (tradicionales aliados de Avito), destinada a reemplazar en el trono romano a Mayoriano por un tal Marcelino, supuestamente afecto a los intereses galos. Se trata, en efecto, de la llamada coniuratio Marcelliniana, ante la cual Mayoriano hubo de intervenir con prontitud y contundencia, tras haber reunido un número considerable de tropas y haberse consolidado en el recién asumido cargo. Así, una de sus primeras acciones como emperador sería confiarle a Egidio, bajo la dignidad especial de magister militum per Gallias, la tarea de reducir a los conjurados, con ayuda de tropas francas y romanas. La carga sobre Lyon, ciudad natal de nuestro poeta y centro de la disidencia aristocrática, fue sin duda brutal: la toma de la villa entre el verano y el otoño de 458 dejó totalmente devastadas sus calle y plazas y supuso la expulsión de los conjurados burgundios, que se habían atrincherado en ella. Egidio prosiguió su cruzada hacia Aquitania, dejando destacada en Lyon una tropa de ocupación, en un gesto que los lioneses debieron de considerar altamente humillante. Gracias a la labor diplomática del poeta y político Pedro, magister epistolarum y consejero personal del nuevo emperador, Mayoriano consintió la retirada de las fuerzas de represión que ocupaban la ciudad de Sidonio, así como la vuelta paulatina de los burgundios expulsados, reducidos ahora a la autoridad de Roma. Parece que Pedro mantenía un estrecho contacto con Sidonio (unidos como estaban por su profesión literaria), por lo que no nos debe extrañar que convenciera a nuestro poeta de escribir y pronunciar -en 
su propia ciudad natal, tan castigada en aquellos momentos- un panegírico al nuevo emperador (fechado en ese mismo año 458), con la compleja finalidad de conciliar los ánimos postbélicos de los malogrados lioneses mediante una abierta alabanza a la clemencia y magnanimidad del monarca. Por lo que podemos deducir, Sidonio saldaría con éxito tan difícil tarea, respaldado por la política integradora de Mayoriano, quien optaría en adelante por destacar a diversas personalidades galorromanas con importantes cargos en la administración del Imperio ${ }^{7}$, con lo que terminaría por aplacar las susceptibilidades restantes y sofocar las escasas voces aún disidentes.

En este desafortunado contexto, Sidonio debe reencontrarse con su ciudad natal, Lyon, resentida por los desastres de la guerra, reducida a poco más que una ruina y casi diríamos que "tomada" por los readmitidos burgundios (sobre los que satirizará, pocos años más tarde, en su célebre carm. 12, objeto de nuestro análisis), quienes imponen sus costumbres y maneras en todos los órdenes de lo cotidiano. El impacto emocional de este choque de culturas debió de ser, sin duda, enorme para un defensor acérrimo de los valores de la Romanidad y los privilegios de la antigua aristocracia, como era Sidonio. El poeta se nos muestra siempre como un agudo observador de los problemas de su tiempo, lo que le suma importancia a su testimonio respecto a los burgundios.

Precisamente uno de los factores más determinantes en el tambaleo general de las instituciones tardoimperiales, como es la penetración masiva de pueblos extranjeros y su voluntad de asentamiento dentro del limes Romanus, constituirá el tema central del cáustico carmen 12, más conocido como Sátira de los Burgundios. Esta divertida pieza dedicada al senador Catulino, buen amigo de nuestro poeta, denuncia en clave de humor la extrema precariedad que atravesaba la maltratada capital lionesa tras la readmisión de los conjurados burgundios, que pasaron a enseñorearse de la colapsada ciudad gala. De ahí que nos sea lícito afirmar con toda garantía que la pieza fue compuesta con posterioridad a la toma de Lyon por las tropas represoras de Egidio (458), lo que nos situaría en la compleja coyuntura socio-política que venimos describiendo. Es más, todos los indicios nos autorizan a pensar que la readmisión de los burgundios expulsados de la ciudad gala no se produciría hasta bastante después de la intervención represora de Egidio, gracias a la labor diplomática de Pedro, el famoso promotor del Panegírico a Mayoriano, artífice de la conciliación final del monarca con la exigente nobleza gala. Pero antes de atrevernos a ofrecer una datación más exacta, conviene que volvamos nuestra vista a lo que el propio contenido del texto nos indica.

Sidonio parece haber recibido de Catulino, amigo suyo de la infancia y senador bajo Mayoriano ${ }^{8}$, el encargo de componer un epitalamio, género -como sabemosen absoluto desconocido para su pluma'. Sidonio responde con esta breve y cáustica pieza, que vuelve a adoptar la estructura favorita del lionés: la de una 
recusatio. El poeta rechaza, en efecto, la propuesta de su amigo, aduciendo la imposibilidad de transitar ciertos caminos literarios en un contexto como el suyo, rodeado como estaba por las toscas guarniciones de los burgundios, que imponían por doquier la rudeza de sus costumbres, haciéndole sentir extranjero en su propia ciudad natal. Este encontronazo con el prosaísmo y la vulgaridad del mundo circundante obliga al poeta -al igual que en el carmen 13- a descender de los sueños imposibles de una Romanidad ya casi extinta para denunciar una situación que pone en peligro la propia pervivencia del legado cultural de un Imperio agonizante. De nuevo el humor y la distancia irónica se convertirán en los mecanismos de defensa del mordaz poeta galo ante una realidad del todo inasumible, que mueve a la risa descreída sobre un incuestionable fondo de amargura. Fiel al espíritu clásico de la sátira, Sidonio sustenta la comicidad de la pieza -como ya hiciera con el carmen 13sobre la base de efectivos mecanismos contrastivos, que obligan a convivir en un mismo poema a los más excelsos iconos de las áureas letras latinas con las imágenes más grotescas y materiales del comportamiento de los soeces bárbaros. Se trata, por supuesto, del proceso clásico de construcción y refuerzo de la propia identidad nacional -herida y tambaleante tras un movimiento masivo de población que trae consigo los inevitables mestizajesmediante la denigración de las características étnicas de sus agresores, incluida la estatura física. Esta yuxtaposición de realidades espirituales con otras descarnadamente terrenas (articuladas en este caso en torno al campo semántico de lo culinario y lo alimenticio, contemplado como emblema de la voracidad animal de los bárbaros y la carnalidad de sus inquietudes (tópico étnico), con la pretensión de mover a la repugnancia al hipotético lector del texto) no puede dejar de recordarnos las características iuncturae acres de Persio, maestro de la risa amarga y el pesimismo desencantado. No en vano Persio será uno de los autores más leídos e imitados durante todo el Medievo, una época que encaja a la perfección con la sensibilidad poética de Sidonio, otro de los autores favoritos de dicho período. Este recurso constante a toda suerte de estrategias contrastivas (semánticas, léxicas, de estilo, de tono, de registro ${ }^{10}$ ) no tiene la única finalidad de conseguir un efecto cómico o humorístico; antes bien, constituye la expresión formal más adecuada y evocadora del gran drama de la época de Sidonio: la imposibilidad de preservar y revisitar el sutilísimo legado de la Antigüedad grecorromana en un mundo que ya nunca volverá a ser el mismo, transido como estaba de vulgaridad y reducido a una anárquica cocina en la que imperan tan sólo las necesidades más primarias del hombre, encarnadas en la voracidad animal de los burgundios y sus costumbres tabernarias. Estamos, por lo tanto, ante otro ejemplo evidente de conciencia de la propia época, que se sustancia además en una presencia efectiva de los problemas más significativos del momento en el seno mismo del poemario de Sidonio, que ejerce sobre ellos un buscado esfuerzo de literaturización, a fin de adaptarlos al esquema genérico de la sátira y hacerlos artís- 
ticamente asimilables. Precisamente eso hace más enigmática la afirmación final del texto (v. 22: ne quisquam satiram nel hos nocaret), de tintes abiertamente metapoéticos (el hos remite desde el poema a los propios versos de éste, así como el paucis hendecasyllabis del v. 21 alude a su metro y extensión o el Musa tacet del v. 21 a la voluntad expresa del poeta por atajar su desarrollo), en la que el autor dice retener la locuacidad de su Musa para evitar que alguien pueda llamar sátira a los versos que acaba de leer, que deben entenderse desde una perspectiva puramente lúdica (iocata: v. 21). Sidonio crea un desconcierto interpretativo en su lector potencial, que se ve invitado a rechazar al final del texto el patrón decodificador que esos mismos versos habían auspiciado al ir cumpliendo cada una de sus convenciones, con lo que consigue dar un vuelco al horizonte de expectativas y al propio status literario del texto poético, que se complace en autonegarse sin ofrecer nuevas alternativas de lectura. Será precisamente la frustración continua de las expectativas decodificadoras del lector implícito uno de los rasgos más destacados y originales de la enrevesada poética del lionés, acostumbrada a proceder por vía negativa y a transgredir las convenciones de lectura genérica mediante un uso deliberado de la incoherencia y la contradicción, que delatan una actitud autoconsciente, distanciada y cuentionadora respecto al hecho literario en sí y sus condiciones tradicionales de recepción, con las que juega más allá de los límites esperables. Gran parte de la crítica ha coincidido en buscar la solución a tan polémico aserto en la conocida epístola 1,11, que relata el peligroso incidente de la sátira de Arlés, dos de cuyos protagonistas, Catulino y Sidonio, reaparecen precisamente en este carmen 12 como destinatario y autor de otro texto de tintes satíricos. El guiño casi privado a esa polémica, lejos de anular el carácter transgresor de la afirmación final del poema, nos revelará la plena conciencia del lionés respecto a la viabilidad de unos géneros y otros en el sistema literario de su tiempo, su actitud como poeta y los términos efectivos de su relación con los poderes establecidos, encarnados una vez más por el emperador Mayoriano. Se trata en suma de una polémica literaria de tintes marcadamente políticos en la que se pone de manifiesto el funcionamiento del sistema cultural tardoantiguo y las posibilidades reales con las que cuenta el poeta de superar alguna de sus muchas imposiciones limitadoras, gracias a un hábil manejo de las convenciones literarias y a un diplomático dominio de los sutiles mecanismos de los círculos cortesanos. Se trata por lo tanto de un ejemplo verídico de esa confrontación dialógica entre príncipe y poeta que se escenifica desde un plano teórico en el poema 13 de este mismo autor, un juego de poderes y sobreentendidos sin el cual difícilmente podremos entender la elaborada literatura de la época.

Podemos constatar, en definitiva, cómo los tópicos nacionales se avivan en épocas de emigraciones masivas y contactos entre pueblos, que producen casi siempre un tambaleo en el sistema de certezas de ambos grupos étnicos. Roma se mira en el espejo de los burgundios como antes lo había 
hecho en el de los "decadentes" orientales: con evidentes funciones identitarias y de autoafirmación. Las teorías deconstructivas de Derrida nos aportan el marco teórico idóneo para entenderlo: según el fiósofo francés, recientemente fallecido, en cada par binario la normalidad del término que se autoerige como norma (en este caso Roma, defendida por Sidonio) no depende de sus cualidades intrínsecas sino de la oposición con otro término (burgundios) que se caracteriza como negativo (teoría de la "otredad"). Por otra parte, la presencia masiva de una cultura no autóctona (interpretada como elemento negativo o de contraste) en el seno de otra, horada sus principios más inamovibles y plantea incómodos interrogantes a su hegemónica cosmovisión. Esto genera una situación de desubicación e inseguridad que, a menudo se intenta suplir con la autoafirmación contrastiva de los valores autóctonos más arraigados de cada comunidad, lo cual no deja de ser una prueba más de la fragilidad de esos mismos valores en tales contextos. La alabanza de las estructuras sociales propias como algo inmovil e imperecedero, amenazado por el execrable elemento extranjero, no deja nunca de ser el vaticinio más seguro de la proximidad de su cambio. Es la misma paradoja que subyace al hecho de que se creara el tópico de Roma como Urbs aeterna precisamente en el momento en el que esa aeternitas era más cuestionable que nunca. Sidonio lucha por la preservación de un sistema de valores tocado de muerte. De la síntesis social y espiritual entre las civilizaciones germánicas y la romana nacerá el hombre medieval y, con él, el fundamento último de la unidad radical de nuestra cultura europea. Una nueva identidad cultural que emanará de estos desesperados intentos de autoafirmación de dos colectivos condenados a fundirse. Una nueva unidad que parte de la diferencia.

\section{BIBLIOGRAFÍA}

-Anderson, W. B. (ed., trad., introd. y notas), Sidonius, vol. I Poems and Letters, London, Loeb Classical Library, 1936.

-BANNIARD, M., Viva voce. Communication écrite et communication orale du IV au IX siècle en Occident latin, Paris, Brepols, 1992.

-FernÁndez López, M. C., Sidonio Apolinar, humanista de la Antigüedad tardía: su correspondencia (col. Antigüedad y Cristianismo), Murcia, Universidad de Murcia, 1994.

-Fischer-Fabian, S., I germani, Milano, Garzanti, 1985 (1975).

Harries, J., Sidonius Apollinaris and the Fall of Rome. AD 407-485, Oxford, Oxford University Press, 1994.

-Loyen, A. (ed., trad., introd. y notas), Sidoine Apollinaire, vol. I Poèmes, Paris, Les Belles Lettres, 1960. 
-Mommsen, T. (ed.), Iordanis Romana et Getica, Berlín, Monumenta Germaniae Historica Auct. ant. 5,1, 1882.

-Musset, L., The German Invasions. The Making of Europe AD 400-600, Pennsylvania, The Pennsylvania State University Press, 1975 (1965).

-PÉREz SÁNCHEZ, D., "Realidad social, asentamiento bárbaro y prejuicios ideológicos en la Galia del s. V a través de la obra de Sidonio Apolinar", Gerión 15, 1997, 223-241.

-SÁNCHEZ SALOR, E., "La última poesía latino-profana: su ambiente”, Estud. Clás. 25, 1981-83, 111-162.

-SANTOS, N., Los pueblos germánicos en la segunda mitad del siglo IV d. C., Oviedo, Universidad de Oviedo, 1990.

-Seyfarth, W., Jacob-Karau, L., Ulmann, I. (eds.), Ammiani Marcellini rerum gestarum libri qui supersunt, Berlín, Teubner, 1978.

-WERnER, J., "Beiträge sur Archäologie des Attila-Reiches", Die Bayerische Akademie der Wissenschaft. Abhandlungen, N.F. XXXVIII A Philosophische-philologische und historische Klasse, Münche Shanzer, 1953, 312-330.

-Wright, R., Late Latin and Early Romance in Spain and Carolingian France, Liverpool, 1982.

\section{NOTAS}

${ }^{1}$ Pese a la hostilidad de los burgundios hacia los hunos, todo parece indicar que en algún momento de su historia existió cierto contacto "amistoso" con los hunos, de los que importarían no pocas modas y costumbres: así sucedió, por ejemplo, con el gusto de los hunos por alargar artificialmente el cráneo de las mujeres, vendándoles con fuerza la cabeza cuando no eran más que unas niñas y no tenían soldada aún la fontanela infantil. Las evidencias arqueológicas demuestran (WERNER, 1953) que, entre todas las tumbas germánicas al oeste del Rhin, tan sólo las burgundias contienen una cantidad considerable de cráneos elongodos según este sistema, generalmente acompañados por ornamentaciones hunas como parte del ajuar funerario

2 ...infidoque tibi Burgundio ducto (carm. 7,442), en relación con el asesinato de Petronio Máximo en circunstancias poco claras.

${ }^{3}$ Los considera, de hecho, descendientes de los romanos (Res Gestae, 28,5,11: quod iam inde a temporibus priscis subolem se esse Romanam Burgundi sciunt), en un claro intento de justificar con lazos genéticos las alianzas que de facto se daban entre ambos pueblos, dignificando con sangre latina a este pueblo "bárbaro". Para una valoración más detenida del testimonio de Amiano respecto a los burgundios, vid. Santos, 1990:109.

${ }^{4}$ Exactamente el 28 de diciembre de 457. 
${ }^{5}$ Los versos 11-14 resultan particularmente explícitos a este respecto: Sic mibi diuerso nuper sub Marte cadenti / iussisti inuicto, uictor, ut essem animo. / Seruiat ego tibi seruati lingua poetae / atque meae nitae laus tua sit pretium.

${ }^{6}$ Recientemente la profesora FERNÁNDEZ LÓPEZ (1994:23) ha reabierto una vieja polémica respecto a la citada coniuratio Marcelliniana, alegando que sólo tenemos noticia de ella (al menos bajo ese nombre) por una frase de Sidonio (epist. 1,11,6), cuya lección ha sido además objeto de enmiendas y reinterpretaciones diversas. No es éste, desde luego, el lugar ni el momento de sopesar las razones que arguyen unos y otros historiadores para defender sus tesis al respecto. Me limito simplemente a reflejar aquí la communis opinio de los expertos en el estado actual de la cuestión, primando sobre todo los criterios de verosimilitud histórica de las hipótesis formuladas y su conformidad rigurosa con la información que nos proporcionan los textos, de acuerdo con el rigor filológico exigible a cualquier estudio de estas características. En todo caso, fuera o no Marcelliniana la oposición al emperador, es evidente que algo tuvo que motivar las represalias de Mayoriano sobre esa zona de la Galia tan íntimamente ligada al derrocado Avito. Bajo el poder de Mayoriano, en efecto, Lyon se nos presenta reducida a ruinas (carm. 13, 23-4) y sometida a fuertes cargas fiscales (carm 13), de las que ni siquiera nuetro poeta se ve exento. Que Sidonio participara de tal conjuración de aristócratas como ya pretendía ANDERSON (1936:XXXII) e insinúa actualmente el propio HARRIES (1994:86) nos resulta, en cambio, mucho más inverosímil, y diversos factores nos invitan a refutarlo: el carácter lacónico y despectivo de la única mención que hace de ella (epist. 1,11,6: cumque de capessendo diademate coniuratio Marcelliniana coqueretur), puesta además en conexión con un personaje sobre el que acaba de satirizar vehementemente (el demagogo Peonio) y la ausencia significativa de mención a tal conjura en otros pasajes de las epístolas nos invitan a creen que no gozó en su momento de las simpatías del poeta (cfr. et. LOYEN, 1960:XIIIXIV y SÁNCHEZ SALOR, 1981-83: 115). Al parecer, Sidonio, agradecido tras obtener el perdón de Mayoriano por su más que probable implicación en los hechos de Plasencia (Plaisance), le rinde tributo propagandístico, regido siempre por el pragmatismo político que le caracteriza, en constante búsqueda de la mayor estabilidad del Estado. Según SÁNCHEz SALOR (1981-83: 115-116): “esta postura de Sidonio a favor del emperador y en contra de sus compatriotas ha merecido distintas interpretaciones: para unos es una abierta traición a su partido y un claro servilismo al emperador; para otros, como Loyen, no es sino el pago de una deuda que Sidonio tenía con Mayoriano, ya que este le había amnistiado tras la caída de Avito; [... ] En definitiva, pues, si Sidonio apoya a Mayoriano es porque ve en él la única fuerza capaz de mantener el Imperio contra los bárbaros, y no por servilismo ni agradecimiento".

${ }^{7}$ Para una enumeración detallada de los muchos galos que accedieron a altas dignidades imperiales durante el gobierno de Mayoriano, vid. HARRIES, 1994:90 ss. La finalidad estratégica y conciliadora de tales nombramientos resulta más que manifiesta.

${ }^{8}$ Sobre los escasos datos con que contamos respecto a la vida de Catulino, vid. una buena síntesis en KAUFMANN, 1995:289, donde se revisa y valora lo dicho por los principales teóricos precedentes. Más extenso aunque no poco conjetural es el relato de LOYEN, 1943:67 ss. El texto base, aparte del citado poema 12, para la indagación sobre la figura de este senador galo es únicamente la epist. 1,11. 
${ }^{9}$ LOYEN, siempre tan proclive a la reconstrucción conjetural de los acontecimientos biográficos de nuestro poeta y su entorno, no duda en afirmar que el epitalamio que Catulino tuvo a bien solicitarle a su amigo tenía por ocasión la inminente boda de este senador galo (1943:68). La suposición nos parece del todo excesiva, considerando la escasez de datos sobre la vida de Catulino y el propio carácter ficcional de la pieza. Es más, ni siquiera podemos afirmar con seguridad que el senador galo llegase a formular alguna vez tal petición a nuestro poeta: siempre podría tratarse de una pura excusa argumental de Sidonio para componer una mordaz sátira contra los burgundios, en un guiño de complicidad con su amigo Catulino, copartícipe de la peligrosa polémica suscitada en Arles respecto a ese género prohibido (de la que se hace eco la epist. 1,11), habida cuenta de que el lionés nunca tuvo reparos reales para componer epitalamios (carm. 10,11,14,15), mucho menos tratándose de la boda de un personaje tan cercano a su círculo.

${ }^{10}$ Así, por ejemplo, en el plano lingüístico, el poema se nos presenta completamente articulado en función de dos registros contrapuestos: el uno más culto y elevado, eminentemente literario e inmaterial, plagado de referencias mitológicas (v. 2: Diones; v. 18 Gigantes; v. 19: Alcinoı) y poéticas (v. 2: Fescenninicolae; v. 10: senipedem stilum Thalia; vv. 1-2) arranque interrogativo de resonancias catulianas (cfr. carm. 9)), cultismos (v. 2: Diones, nombre erudito frente al más trivializado de 'Venus') y compuestos nominales (v. 2: Fescenninicolae; v. 3: crinigeras, tomado de Lucano 1,463 y Claudiano 21,203); el otro, más popular y ligado a la oralidad cotidiana, lleno de términos concretos vinculados al universo sensorial y alimenticio (v. 7: acido ... butyro, v. 12 oculos ... aures; v. 13: nasum; v. 14: allia sordidumque cepe; v. 15: apparatus; v. 19: culinam), rayanos con lo grosero (v. 15: ructant), expresiones fáticas y parentéticas (v. 1: etsi ualeam; v. 8: uis dicam tibi ... ?), coloquialismos (v. 4: sustinentem) y parodias bíblicas (vv. 12-13: felices oculos tuos ... / felicemque ... nasum, revisión cómica de las Beatitudines evangélicas, reformuladas con el adjetivo felix, más corriente y panrománico, frente al cultismo beatus) etc. Da prueba de la expresa voluntad de vulgarización léxica de la pieza, el uso -totalmente infrecuente en el rebuscado estilo de Sidonio- de términos abiertamente coloquiales, que debieron corresponder al estándar lingüístico de la época a tenor de su perduración en el futuro galorromance: así, subinde con el sentido característicamente románico de "una y otra vez, frecuentemente" ( $>$ fr. souvent, atentiguado con ese mismo significado dsde 1008, en la Chancon de Roland); cantat ( $>$ fr. chante), frecuentativo que suplantará al clásico canit en todas las lenguas romances; uetulum ( $>$ fr. vieux / viei), diminutivo abiertamente popular y panrománico, único superviviente léxico frente al positivo uetus o al relegado senex. Por otra parte, se nos antoja más que probable que, de acuerdo con las teorías lingüísticas de WRIGHT (1982) y BANNIARD (1992), la pronunciación de tales términos en el estándar culto de la época se acercase ya bastante a la fonética romance. Sea como fuere, este contraste de registros lingüísticos con buscados efectos cómicos se articularía para darle forma a la idea principal del poema: que la vulgaridad y lo grotesco se habían adueñado del mundo de Sidonio, haciendo que los refinados modelos del pasado resultaran ya imposibles de seguir, intransitables, ajenos. De ahí la melancólica sensación de pérdida que se destila de todo el texto, sólo superficialmente humorístico. 